\section{Attributes of unfamiliar, long, scientific names}

BARR Y LOIGMAN and ALBERTE. GOSS, Douglass College, Rutgers, The State University, New Brunswick, N.J. 08903

Values, correlations, and loadings on factorial components are presented for meaningfulness, imagery, and eight other attributes of 36 unfamiliar, scientific names. Comparisons are made with findings for common nouns.

Available norms on (values of) meaningfulness, imagery, and other attributes of words are primarily for trigrams, for paralogs, and for nouns from the Thorndike-Lorge (T-L) list. Reported here are values for various attributes of relatively unfamiliar, long names (nouns) from a scientific vocabulary (bacteriology). These words were selected for use in an investigation of the verbal learning of real, but unfamiliar, words. Values for them are reported here because other investigators may wish to use these words. Also, the values obtained for these attributes and relationships observed among them supplement available data, in particular, those of Spreen \& Schulz (1966) for 329 nouns of high T-L(A) frequency and of Paivio, Yuille, \& Madigan (1968) for 925 nouns of low-to-high T-L frequency.

\section{METHOD}

\section{Source of Words}

Various technical vocabularies were reviewed as possible sources of real, unfamiliar words. The source selected was Breed's Manual of Determinative Bacteriology (1948). It contains a large number of words that are probably unfamiliar to most of the college undergraduates who participate in experiments on verbal behavior and learning.

\section{Selection of Words}

The 36 words shown in Table 1 were considered enough to construct lists for paired-associate, verbal-discrimination, serial-anticipation, free-recall, and similar situations. They are equally for genus and species, relatively long (eight or more letters, three or more syllables), with few common initial letters, apparently low in overall formal similarity, and, some excepted, not obviously similar to words in the general vocabulary.

\section{Responses and Attributes}

The responses and attributes selected and the particular manner of obtaining them were: meaningfulness (M)-produce as many associations as possible within $30 \mathrm{sec}$; imagery (I)-rate on 7-point scale, one extreme designated "no" (1), other extreme "clear" (7); specificity (S)-7-point scale, likely grammatical function. of this page. "low", (1) to "high" (7); concreteness (C)-7-point scale, "low" (1) to "high" (7); familiarity (F)-7-point scale, "never" (1) to "often" (7); pronunciability (P)-7-point scale, "easy" (1) to "hard" (7); and grammatical function-select one among adjective, adverb, conjunction, noun, pronoun, preposition, verb as the most frequent, most

Randomization and Counterbalancing

The words were presented one at a time within booklets. The five scales were on the page on the left. Each word was repeated 10 times, from the top down, on the page on the right, with each repetition followed by a line beneath for S's association. Names of grammatical functions were at the bottom

The words occurred in a different random order for each $\mathrm{S}$. Order of scales was counterbalanced so that each occurred equally often in each position. The adjectives at the end of each scale appeared equally of ten on the left and on the right.

Table 1

Each Word, Its Length and Primary Response; Frequency of the Primary and Number of Different Responses; Mean of Each Word for M, I, S, C, F, P; and Number of Ss Selecting Noun Function

\begin{tabular}{|c|c|c|c|c|c|c|c|c|c|c|c|}
\hline Word & $\mathbf{L}$ & Primary & $f_{p}$ & $\mathrm{~N}_{\mathrm{D}}$ & M & I & $S$ & $\mathrm{C}$ & $F$ & $\mathbf{P}$ & $N_{N}$ \\
\hline Agliaceus & 9 & Algae & 5 & 18 & 2.83 & 1.97 & 3.63 & 2.87 & 1.13 & 4.90 & 15 \\
\hline Alcaligenes & 11 & Genetics & 4 & 21 & 3.20 & 2.07 & 4.38 & 3.93 & 1.55 & 4.31 & 21 \\
\hline Bentotensis & 11 & Tension & 6 & 15 & 3.37 & 2.03 & 3.77 & 3.23 & 1.03 & 2.93 & 23 \\
\hline Blastocaulis & 12 & Biology & 4 & 18 & 3.40 & 2.23 & 4.50 & 4.37 & 1.03 & 3.77 & 22 \\
\hline Capsulata & 9 & Capsule & 20 & 9 & 4.07 & 3.80 & 4.27 & 4.33 & 2.10 & 1.93 & 23 \\
\hline Cellvibrio & 10 & Cell & 6 & 18 & 3.97 & 2.17 & 4.13 & 3.67 & 1.10 & 3.43 & 25 \\
\hline Dextranicum & 11 & Dextrous & 5 & 17 & 3.43 & 2.73 & 4.13 & 3.90 & 1.37 & 3.53 & 23 \\
\hline Dialister & 9 & Dial & 6 & 17 & 3.57 & 1.90 & 4.00 & 3.63 & 1.13 & 2.43 & 20 \\
\hline Eberthella & 10 & Biology & 2 & 21 & 3.00 & 1.67 & 4.03 & 3.40 & 1.00 & 3.20 & 23 \\
\hline Ferruginea & 10 & Iron & 5 & 17 & 3.43 & 2.20 & 4.33 & 3.50 & 1.00 & 4.03 & 25 \\
\hline Fusobacterium & 13 & Bacteria & 12 & 13 & 4.30 & 3.37 & 5.07 & 5.03 & 1.37 & 2.27 & 28 \\
\hline Gallionella & 11 & Bacteria & 2 & 26 & 3.93 & 2.57 & 4.27 & 4.13 & 1.30 & 2.80 & 28 \\
\hline Gazogenes & 9 & Genes & 7 & 17 & 3.63 & 1.83 & 5.10 & 4.17 & 1.07 & 2.70 & 25 \\
\hline Hemophilus & 10 & Blood & 10 & 13 & 4.30 & 2.70 & 4.93 & 4.77 & 2.43 & 2.33 & 19 \\
\hline Hyacinthi & 9 & Hyacinth & 13 & 9 & 4.37 & 4.67 & 5.63 & 5.47 & 2.20 & 2.77 & 24 \\
\hline Klebsiella & 10 & Bacteria & 2 & 22 & 3.10 & 1.90 & 4.43 & 3.30 & 1.20 & 3.33 & 24 \\
\hline Lacunatus & 9 & Lacuna & 2 & 23 & 3.00 & 2.27 & 3.93 & 3.30 & 1.07 & 3.13 & 12 \\
\hline Leuconostoc & 11 & Blood & 3 & 24 & 3.67 & 1.93 & 3.93 & 3.53 & 1.20 & 4.10 & 13 \\
\hline Malleomyces & 11 & $\mathrm{Bad}$ & 3 & 23 & 3.63 & 2.37 & 4.23 & 3.57 & 1.10 & 3.73 & 27 \\
\hline Muscorum & 8 & Decorum & 6 & 16 & 3.60 & 2.47 & 4.13 & 3.47 & 1.40 & 2.73 & 24 \\
\hline Nitrobacter & 11 & Nitrogen & 9 & 15 & 4.63 & 3.27 & 4.73 & 4.60 & 1.87 & 2.10 & 29 \\
\hline Nucleatum & 9 & Nucleus & 11 & 16 & 4.93 & 3.87 & $4: 80$ & 4.83 & 1.97 & 2.17 & 26 \\
\hline Ochraceus & 9 & Color & 5 & 18 & 3.30 & 2.40 & 3.63 & 3.20 & 1.17 & 4.30 & 14 \\
\hline Phytomonas & 10 & Phylum & 4 & 18 & 2.83 & 1.97 & 4.00 & 3.50 & 1.07 & 3.93 & 19 \\
\hline Pneumosintes & 12 & Pneumonia & 13 & 11 & 3.77 & 2.03 & 4.27 & 3.80 & 1.13 & 4.00 & 27 \\
\hline Radiobacter & 11 & Radio & 8 & 19 & 4.07 & 2.63 & 4.33 & 4.13 & 1.07 & 2.20 & 26 \\
\hline Rhizobium & 9 & Rhizoid & 4 & 21 & 4.23 & 3.73 & 4.93 & 5.23 & 2.13 & 2.53 & 28 \\
\hline Sphaerica & 9 & Sphere & 9 & 15 & 3.73 & 2.47 & 3.90 & 2.97 & 1.17 & 4.10 & 18 \\
\hline Stelangium & 10 & Bacteria & 4 & 20 & 3.63 & 2.13 & 4.20 & 4.07 & 1.13 & 2.70 & 26 \\
\hline Thiocyst is & 10 & Disease & 6 & 19 & 3.40 & 2.37 & 4.63 & 3.97 & 1.17 & 3.10 & 24 \\
\hline Trifolii & 8 & Three & 7 & 24 & 3.80 & 2.20 & 3.97 & 3.53 & 1.07 & 3.50 & 22 \\
\hline Veillonella & 11 & Old & 5 & 23 & 4.03 & 2.12 & 3.87 & 3.63 & 1.00 & 4.17 & 20 \\
\hline Violacea & 8 & Violin & 5 & 18 & 4.37 & 2.13 & 4.00 & 3.90 & 1.03 & 3.27 & 19 \\
\hline Winogradskyi & 12 & Polish & 4 & 20 & 3.43 & 2.73 & 4.27 & 3.97 & 1.20 & 4.83 & 21 \\
\hline Xanthomonas & 11 & Flower & 4 & 17 & 3.03 & 1.93 & 4.03 & 3.73 & 1.03 & 4.50 & 17 \\
\hline$Z$ ingiberi & 9 & Beri beri & 5 & 21 & 4.53 & 2.53 & 4.50 & 4.00 & 1.03 & 2.63 & 25 \\
\hline$\overline{\mathrm{X}}$ & 10.1 & & 6.3 & 18.1 & 3.71 & 2.54 & 4.30 & 3.91 & 1.31 & 3.29 & 22.4 \\
\hline SD & 1.2 & & 3.8 & 4.0 & 1.24 & .69 & .44 & .61 & .39 & .82 & 4.4 \\
\hline SS $\bar{X}$ & & & & & 8.17 & & 4.48 & 5.02 & & 3.76 & \\
\hline PYM $\bar{X}$ & & & & & 5.81 & 4.97 & & 4.95 & & & \\
\hline
\end{tabular}
write associations, and $5 \mathrm{sec}$ to select the grammatical function. Total time per word was $1 \mathrm{~min}$.

Thirty female undergraduates enrolled in introductory psychology at Douglass College participated as a group in a single session.

\section{RESULTS AND DISCUSSION}

For each word, Table 1 also shows: (a) its length $(\mathrm{L}) ;(\mathrm{b})$ the most frequent or primary first response; (c) frequency of the primary $\left(f_{p}\right)$; (d) number of different first responses by all $\mathrm{Ss}\left(\mathrm{N}_{\mathrm{D}}\right)$; (e) mean of number of associations by each $S(M)$; (f) means of ratings of $I, S, C, F, P$; and (g) number of Ss who selected "noun" $\left(\mathrm{N}_{\mathrm{N}}\right)$. Ratings were scored from 1 to 7 as shown above by numbers in parentheses after the anchoring adjectives of each scale. Shown in Rows 3 and 4 from the bottom are overall means and standard deviations.

The low mean and standard deviation of ratings of $F$ indicate that the words were homogeneously unfamiliar. Spreen \& Schulz

Position of names of grammatical functions was also counterbalanced.

As each word occurred, Ss had $5 \mathrm{sec}$ to rate it along each of the five scales, $30 \mathrm{sec}$ to . . 
Table 2

Matrix of Correlations Between Variables of Table 1

\begin{tabular}{|c|c|c|c|c|c|c|c|c|c|}
\hline Variable & $\mathbf{f}_{\mathfrak{p}}$ & $\mathrm{N}_{\mathrm{D}}$ & $\mathbf{M}$ & I & $\mathbf{S}$ & $\mathrm{C}$ & $\mathbf{F}$ & $\mathbf{P}$ & $\mathbf{N}_{\mathbf{N}}$ \\
\hline L & -.05 & .00 & -.09 & -.11 & .09 & .16 & -.14 & .20 & .24 \\
\hline $\mathbf{f}_{\mathbf{p}}$ & & $-.83^{* *}$ & $.53^{* *}$ & $.65^{* *}$ & $.40^{*}$ & $.46^{* *}$ & $.56 * *$ & $-.44^{* *}$ & .26 \\
\hline$N_{D}$ & & & -.28 & $-.53^{* *}$ & $-.38^{*}$ & $-.37^{*}$ & $-.48 * *$ & .29 & -.15 \\
\hline$M^{2}$ & & & & $.68^{* *}$ & $.55^{* *}$ & .70 & $.55^{* *}$ & $-.63 * *$ & $.50^{* *}$ \\
\hline I & & & & & $.77^{* *}$ & $.83^{* *}$ & $.86^{* *}$ & $-.57 * *$ & $.35^{*}$ \\
\hline$S$ & & & & & & $.87^{* *}$ & $.62^{* *}$ & $-.54 * *$ & $.56^{* *}$ \\
\hline $\mathrm{C}$ & & & & & & & $.72 * *$ & $-.60^{* *}$ & $.53^{* *}$ \\
\hline $\mathbf{F}$ & & & & & & & & $-.50 * *$ & .22 \\
\hline $\mathbf{P}$ & & & & & & & & & $-.54 * *$ \\
\hline
\end{tabular}

Table 3

Rotated Matrix of Principle Components with Labels; Attributes with Appreciable Loadings on a Component in Italics

\begin{tabular}{|c|c|c|c|c|c|c|c|}
\hline \multirow{2}{*}{ Attribute } & \multicolumn{7}{|c|}{ Component } \\
\hline & $\mathrm{S}, \mathrm{C}$ & $\mathrm{f}_{\mathrm{p}}, \mathrm{N}_{\mathbf{D}}$ & $\mathbf{L}$ & $\mathbf{N}_{N}$ & $\mathbf{M}$ & $\mathbf{P}$ & $\mathrm{F}$ \\
\hline $\mathbf{L}$ & .06 & -.01 & -.98 & .11 & -.04 & -.09 & -.06 \\
\hline $\mathbf{M}$ & .30 & .18 & .07 & .22 & .84 & .24 & .22 \\
\hline$f_{p}$ & .10 & .87 & .02 & .09 & .31 & .14 & .24 \\
\hline $\mathbf{N}_{\mathrm{D}}$ & -.20 & -.95 & .00 & -.02 & .03 & -.06 & -.13 \\
\hline I & .57 & .37 & .10 & .08 & .33 & .15 & .58 \\
\hline S & .88 & .19 & -.04 & .27 & .12 & .16 & .22 \\
\hline C & .74 & .17 & -.16 & .18 & .34 & .24 & .38 \\
\hline $\mathbf{F}$ & .37 & .29 & .09 & .03 & .16 & .16 & .83 \\
\hline $\mathbf{P}$ & -.27 & -.17 & -.15 & -.27 & -.24 & -.84 & -.19 \\
\hline $\mathbf{N}_{\mathbf{N}}$ & .27 & .07 & -.15 & .90 & .18 & .22 & .04 \\
\hline
\end{tabular}

(SS) and Paivio, Yuille, \& Madigan (PYM) did not obtain values for $\mathrm{F}$ or $\mathrm{N}_{\mathrm{N}}$. Nor did they report primaries, $f_{p}$, and $N_{D}$. The $S S$ means for $M, S, C$, and $P$ and the $P Y M$ means for $M, I$, and $C$ are shown in the last and next-to-last rows, respectively. Means for $M$ and $\mathrm{C}$ obtained for the words of Table 1 are less than the SS and PYM means. The means for $S$ and $P$ are close to the SS mean; the mean for I is below the PYM mean.

$I, S$, and $C$ each enter significant correlations with every other measure, except L (Table 2). $M, f_{p}, F$, and $P$ each appear in correlations with seven of the nine other measures, with $\mathrm{L}$ always excepted and $\mathrm{N}_{\mathrm{D}}$ or $\mathrm{N}_{\mathrm{N}}$ each excepted in about half of the correlations. $N_{D}$ and $N_{N}$ each enter significant correlations with only five other measures, and $\mathrm{L}$ enters no significant correlation. The rs for IC, IF, and SC were above .80 . The $r$ for $f_{p} N_{D}$ was -.83 , but this reflects the partial interdependence of the two measures.

The $\mathrm{r}$ of .70 for MC is essentially the same as the SS $r$ of .704, and larger than the PYM r of .56. The I of .55 for MS is essentially the same as the SS of .564 . The $r$ of .87 for CS is above the SS r of .63. The rs for MP, SP, and CP here are two times or more the comparable SS rs. The $\mathrm{r}$ of .68 for MI is slightly below the PYM r for .72, and the $r$ of .83 for IC is identical with the PYM $r$. The rs involving $\mathrm{L}$ are all less than the comparable SS rs.

The matrix of Table 2 was factored by the principal-components model with rotation of different number of factors, and by the produced by similar mechanisms. The principal-factors model with rotation of six factors. Table 3 shows the rotated matrix of principal components that seems most

\section{Illusions, aftereffects and iconic memory}

HADYN D. ELLIS, University of Reading, Whiteknights, Reading, England

Twenty Ss viewed the Zöllner and Hering illusions under conditions involving a temporal displacement of background and parallel lines. Both illusions persisted until the disparity reached about $1 / 2 \mathrm{sec}$. It was tentatively argued that these results may be interpreted as support for the notion that illusions and aftereffects are results are also considered in terms of iconic storage.

One of the essential differences between geometrical illusions and figural aftereffects is that the former involves simultaneous presentation, whereas the latter is produced as a result of prolonged inspection of a distorting figure. Ganz (1966) has suggested that figural aftereffects and simultaneous geometrical illusions may well be mediated by the same cortical processes. This view, which is supported by Wallace (1969), embraces lateral inhibition at a central level as a possible cause.

The theory concerning the similarity of the two visual phenomena was graduate fellow. I figure. be computed. descriptive of the pattern of correlations of Table 2. The component that contributes most to total variance, labeled $C, S$, is comprised of $I, C$, and $S$ with larger loadings for $C$ and $S$. $f_{p}, N_{D}$ constitute another component. $L, N_{N}, M$, and $P$ each stand alone with relatively little contribution to total variance. The remaining component, labeled $F$, is comprised of $I$ and $F$. The more important features of the patterns of correlations and of components and loadings are the relatively large number of seemingly independent components and allocation of $I$ partly to an $S, C$ component and partly to an $F$ component.

\section{REFERENCES}

BREED, R. S. (Ed.) Bergey's manual of determinative bacteriology. ( 6 th ed.) Baltimore: Williams \& Wilkins, 1948.

PAIVIO, A., YUILLE, J. D., \& MADIGAN, S. A. Concreteness, imagery, and meaningfulness values for 925 nouns. Journal of Experimental Psychology Monograph, 1968, 76, No. 1, Part 2.

SPREEN, O., \& SCHULZ, R. W., Parameters of abstraction, meaningfulness, and pronunciability for 329 nouns. Joumal of Verbal Learning \& Verbal Behavior, 1966, 5 , 459468.

NOTE

1. Partially supported by USPHS Grant MH 13531 to Albert E. Goss, this research was done during Barry Loigman's tenure as an NDEA

strengthened by an experiment performed by Ganz (1964), in which "figural aftereffects" were produced when the inspection (I) figure and test (T) figure were presented together in time and yet produced the same sort of effects on the $T$ figure as those elicited when it was presented after prolonged inspection of the

The following experiment involved the reciprocal of Ganz's experimental paradigm. That is, two geometrical illusions, the Zöllner and Hering (Fig. 1), were presented to Ss in a manner allowing. the background (or I) figure to precede the parallel lines ( $T$ figure) so that the maximum temporal separation that still allowed a distortion of the $\mathrm{T}$ figure might

This procedure is not only reminiscent of those employed in figural aftereffect studies, but is, to some extent, similar to that used by Haber \& Standing (1969) in their quest to find a pure, sensory measure of iconic memory (Neisser, 1967). Their study involved repeated presentations of a black circle while the time between presentations was altered, according to the method of limits, so that a persistence threshold was obtained (i.e., the maximum 